\title{
A highly sensitive method for analyzing marker phytoplankton pigments: Ultra-high-performance liquid chromatography-tandem triple quadrupole mass spectrometry
}

\author{
Jingjing Zhang, ${ }^{1,2}$ Dongyan Liu, ${ }^{* 1}$ Peng Cao, ${ }^{3}$ Yujue Wang, ${ }^{1}$ John K. Keesing, ${ }^{4}$ Jinhua Li, ${ }^{1}$ Lingxin Chen ${ }^{1}$ \\ ${ }^{1}$ Key Laboratory of Coastal Zone Environmental Processes and Ecological Remediation, Yantai Institute of Coastal Zone \\ Research, Chinese Academy of Sciences; Shandong Provincial Key Laboratory of Coastal Zone Environmental Processes, \\ 264003, Yantai, Shandong, P. R. China \\ ${ }^{2}$ University of Chinese Academy of Sciences, 100049, Beijing, P. R. China \\ ${ }^{3}$ Yantai Entry-Exit Inspection and Quarantine Bureau, 264000 Yantai, Shandong, P. R. China \\ ${ }^{4}$ CSIRO Oceans and Atmosphere Private Bag 5, 6913, Wembley, Australia
}

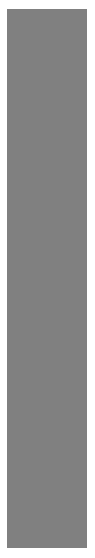

\begin{abstract}
A sensitive and specific ultra-high-performance liquid chromatography-tandem triple quadrupole mass spectrometry (UHPLC-MS/MS) method was developed for the purpose of decreasing the detection limit of quantification (LOQ) and reducing sample analysis time. In total, 14 marker pigments were determined and validated using an internal standard (IS) method with trans-8'-Apo-beta-carotenal as the IS. Electrospray ionization in positive mode was applied for the detection of pigments. The 14 types of pigments were separated in less than $15 \mathrm{~min}$ and presented good linearity, with the coefficients ranging from 0.9915 to $0.9991 \mathrm{using}$ a UHPLC C8 column. The LOQ attained for 14 pigments were from $0.005 \mathrm{ng} \mathrm{mL}{ }^{-1}$ to $0.500 \mathrm{ng} \mathrm{mL}^{-1}$, which enabled quantification of the pigments in seawater at ppt level. Both intra-day and inter-day precisions were less than $15 \%$. The method was validated using seawater samples and the recovery of the analytes ranged from $62.8 \%$ to $120.2 \%$ at two spiked concentrations. Compared with previous methods, UHPLC-MS/MS method improved the efficiency of qualitative analysis and significantly decreased the detection LOQ for analyzing marker phytoplankton pigments at trace/ultra-trace levels in complex matrices.
\end{abstract}

Phytoplankton are the most important primary producers in marine ecosystems, accounting for approximately half of the planetary primary production (Field et al. 1998), determining the biogeochemical cycles, and even influencing climate change (Roemmich and McGowan 1995; Sabine et al. 2004). Chlorophyll (Chl) $a$, as a reliable index, has been used to represent phytoplankton biomass, and the specific pigments in different phytoplankton assemblages obtained by chromatographic separation have been applied for species identification and biomass estimation as chemotaxonomic markers (Mackey et al. 1996; Jeffrey and Vesk 1997; Latasa et al. 2004; Zapata et al. 2004; Jeffrey and Wright 2006). Chemotaxonomy based on pigment markers has greatly improved the monitoring efficiency for phytoplankton assemblages, which includes nano- and pico- phytoplankton that cannot be easily recognized under light microscopy. In recent years, some new instruments (e.g., flow cytometry

Additional Supporting Information may be found in the online version of this article.

*Correspondence: dyliu@yic.ac.cn and DNA analysis) have been used for mapping phytoplankton communities and their abundance. Flow cytometry technique could rapidly count cells and allocate phytoplankton into major algal groups but it is unable to distinguish some algal classes (e.g., haptophytes) (See et al. 2005). In addition, like microscopy, flow cytometry only provides abundance information, while the biomass characteristics of groups are often more important than their numbers (Ives and Carpenter 2007). DNA analysis is powerful for species identification but it is still slow for the analysis of complex natural samples. Therefore, pigment chemotaxonomy remains a useful and powerful technique for mapping phytoplankton populations and is suggested to be the key measurement for study on phytoplankton functional types (Le Quéré et al. 2005).

High performance liquid chromatography (HPLC) is widely used for the determination of phytoplankton pigments, and more than 40 algal pigments were successfully separated using reversed-phase column and modifiers (e.g., ammounium acetate, pyridine, and tetra butyl ammonium acetate) (Wright et al. 1991; Garrido and Zapata 1997; Zapata et al. 2000; Van Heukelem and Thomas 2001). However, 
several important marker pigments, including lutein (Lut)/ zeaxanthin (Zea), are difficult to identify due to their similar structures and co-elution. More recently, a pentafluorophenyloctadecyl silica column was used to improve the resolution of co-elution compounds and more pigments have been successfully determined (Sanz et al. 2015). Pigments in low concentration are still easily interfered with by pigment isomers, degradation compounds and adjacent large peaks in HPLC analysis (Dolan 2002).

The application of liquid chromatography-ion trap mass spectrometry (LC-MS) combined with a photo-diode array detector can help to identify the pigments more effectively. Over the last decade, some new pigments and their derivatives (e.g., [8-ethyl]-chlorophyll c3) have been successfully detected (Squier et al. 2004; Zapata et al. 2004; Airs and Llewellyn 2006; Alvarez et al. 2012). Nevertheless, most LC-MS studies focused on separating pigment types and analyzing the chemical composition and structure rather than improving detection sensitivity (Squier et al. 2005; Frassanito et al. 2005, 2006; Airs and Garrido 2011). Lately, an ultra-high performance liquid chromatography (UHPLC) with the first derivative spectrum chromatogram technique was used for pigments analysis, and it improved the identification of co-elution compounds and reduced the detection limit (Suzuki et al. 2015). The sensitivity of these methods is good enough for measuring pigments in most cases, especially in relatively eutrophic waters. In oligotrophic waters, covering more than $60 \%$ of the subtropic oceans and contributing over $30 \%$ of marine primary production (Marañón et al. 2003), the marker pigments however are hard to detect due to their extra-low concentrations (e.g., neoxanthin (Neox), prasinoxanthin (Pras), violaxanthin (Viol), Lut; Van Heukelem and Hooker 2011). Therefore, it is necessary to develop a highly sensitive method for pigment detection at trace/ultra-trace levels to assist in the ecological studies of open seas.

In this study, we used ultra-high-performance liquid chromatography-tandem triple quadrupole mass spectrometry (UHPLC-MS/MS) developing a highly sensitive method for analysis of pigments in seawater. The method can significantly decrease the detection limit of quantification (LOQ) and improve the efficiency of qualitative analysis. Electrospray ionization (ESI) in the positive mode was applied for pigment detection. Internal standard (IS) method was used for pigment quantification to reduce the error of extraction, injection and ionization. Trans- $8^{\prime}$-Apobeta-carotenal (Apo), which has been successfully used in many laboratories for HPLC analysis (Claustre et al. 2004; Hooker et al. 2009), was chosen as the IS. Natural seawater samples were used for validation of the target pigments.

\section{Material and procedures}

\section{Chemicals and reagents}

Accurate quantification using UHPLC-MS/MS needs pure pigment standards. Currently, approximately 40 types of commercial pigment standards can be purchased from DHI Institute for water and environment, and only 29 of them are available in China. 14 types of pigment standards, which are frequently used in taxonomic interpretation of phytoplankton groups, were chosen as the first step to develop this method. The 14 types of pigment standards including Chl $a$, divinyl (DV) Chl $a$, Chl $b$, Zea, Lut, Pras, Neox, Viol fucoxanthin (Fuco), 19-hex-fucoxanthin (Hex-fuco), peridinin (Peri), 19-but-fucoxanthin (But-fuco), alloxanthin (Allo) and diadinoxanthin (Diad), were purchased from DHI Institute for water and environment (Aarhus, Denmark). Apo was purchased from ChromaDex (Irvine, USA) as IS. Standard solutions were stored in the freezer $\left(-86^{\circ} \mathrm{C}\right)$ prior to analysis within six months. Ammonium acetate was purchased from Sigma-Aldrich (St. Louis, U.S.A.). GFF glass microfiber filters and disposable PTFE syringe filters were purchased from Whatman (Little Chalfont, UK) and Membrane Solutions (Shanghai, China), respectively. Cleaning wipers were purchased from Kimtech Science (Georgia, U.S.A.). All solvents used in the experiments were LC-MS grade (Merck, Darmstadt, Germany). Doubly distilled water was deionized and filtered by a Pallultra pure water system (Pall, Bucks, UK).

\section{Instrumentation}

Sample analysis was performed on Waters Acquity UPLC and Thermo Fisher UHPLC-MS/MS system. UPLC is equipped with Acquity autosampler and photo-diode array e $\lambda$ detector (Waters, Milford, U.S.A.); UHPLC-MS/MS system consisted of Thermo Fisher ACCELA autosampler (Thermo, San Jose, U.S.A.), Thermo Fisher 1250 pump and Thermo Fisher TSQ Quantum Access MAX mass spectrometer. HESI-II probe was used for sample determination (Thermo, San Jose, USA). High-purity nitrogen was used as the nebulizer gas and high purity argon was used as the collision gas. The samples were separated on a reversed-phase UHPLC C8 column (Agilent ZORBAX Eclipse Plus C8 $2.1 \mathrm{~mm} \times 100 \mathrm{~mm}, 1.8 \mu \mathrm{m}$ particle size) with Waters BEH C8 Pre-Column $(2.1 \mathrm{~mm} \times 5 \mathrm{~mm}, 1.7$ $\mu \mathrm{m}$ particle size) as a guard column. The mobile phase was composed of $0.03 \mathrm{~mol} \mathrm{~L}^{-1}$ ammonium acetate in water (A), acetonitrile (B) and methanol (C), and programmed in the linear gradient mode (time $0 \mathrm{~min}, 25 \% \mathrm{~A}, 75 \% \mathrm{~B}$; time 1 $\min , 15 \% \mathrm{~A}, 85 \% \mathrm{~B}$; time $7 \mathrm{~min}$, solvent $\mathrm{A}$ and $\mathrm{B}$ were decreased to $9 \%$ and $71 \%$, respectively, solvent $C$ was increased to $20 \%$; time $9 \mathrm{~min}$, solvent $\mathrm{A}$ was decreased to $0 \%$, solvent $\mathrm{B}$ was increased to $80 \%$, and solvent $\mathrm{C}$ was maintained at $20 \%$ until $15 \mathrm{~min}$; time $15.1 \mathrm{~min}$, returned to the initial conditions of $25 \% \mathrm{~A}$ and $75 \% \mathrm{~B}$, then the mobile phase washed constantly for $5 \mathrm{~min}$ for re-equilibration). The total run time was 20 min.

The injection volume was $10 \mu \mathrm{L}$, and the flow rate was constant at $0.3 \mathrm{~mL} \mathrm{~min}^{-1}$. The temperature of the autosampler compartment was kept at $4^{\circ} \mathrm{C}$ to inhibit the degradation of the pigments. The temperature of the column was set at $30^{\circ} \mathrm{C}$. ESI was selected for experiments because it showed 
Table 1. Details of MS/MS parameters used for analysis of 14 phytoplankton pigments and internal standard.

\begin{tabular}{|c|c|c|c|c|c|c|c|c|c|c|}
\hline \multirow[b]{2}{*}{ Pigments } & \multirow[b]{2}{*}{$\begin{array}{c}\text { Molecular } \\
\text { formula }\end{array}$} & \multirow[b]{2}{*}{$\begin{array}{l}\text { Molecular } \\
\text { ion }\end{array}$} & \multirow[b]{2}{*}{$\begin{array}{c}t_{R} \\
(\min )\end{array}$} & \multicolumn{3}{|c|}{ Quantification } & \multicolumn{3}{|c|}{ Confirmation } & \multirow[b]{2}{*}{$\begin{array}{l}\text { Ion } \\
\text { ratio* }\end{array}$} \\
\hline & & & & $\begin{array}{l}\text { Precursor } \\
\text { ion }(m / z)\end{array}$ & $\begin{array}{c}\text { Product } \\
\text { ion }(m / z)\end{array}$ & $\begin{array}{c}\text { CE } \\
(\mathrm{eV})\end{array}$ & $\begin{array}{l}\text { Precursor } \\
\text { ion }(m / z)\end{array}$ & $\begin{array}{c}\text { Product } \\
\text { ion }(m / z)\end{array}$ & $\begin{array}{c}\text { CE } \\
(\mathrm{eV})\end{array}$ & \\
\hline Peridinin (Peri) & $\mathrm{C}_{35} \mathrm{H}_{50} \mathrm{O}_{7}$ & {$[\mathrm{M}+\mathrm{H}]^{+}$} & 2.34 & 631.4 & 553.4 & 10 & 631.4 & 613.4 & 10 & 2.3 \\
\hline Neoxanthin (Neox) & $\mathrm{C}_{40} \mathrm{H}_{56} \mathrm{O}_{4}$ & {$[\mathrm{M}+\mathrm{H}]^{+}$} & 2.75 & 601.4 & 221.0 & 18 & 601.4 & 147.0 & 28 & 0.9 \\
\hline $\begin{array}{l}\text { 19-but-fucoxanthin } \\
\text { (But-fuco) }\end{array}$ & $\mathrm{C}_{46} \mathrm{H}_{64} \mathrm{O}_{8}$ & {$[\mathrm{M}+\mathrm{H}]^{+}$} & 2.82 & 745.5 & 108.9 & 31 & 745.5 & 727.5 & 10 & 2.3 \\
\hline Fucoxanthin (Fuco) & $\mathrm{C}_{42} \mathrm{H}_{58} \mathrm{O}_{6}$ & {$[\mathrm{M}+\mathrm{H}]^{+}$} & 2.86 & 659.5 & 108.9 & 26 & 659.5 & 641.5 & 10 & 4.5 \\
\hline Prasinoxanthin (Pras) & $\mathrm{C}_{40} \mathrm{H}_{56} \mathrm{O}_{4}$ & {$[\mathrm{M}+\mathrm{H}]^{+}$} & 3.07 & 601.4 & 583.4 & 10 & 601.4 & 119.1 & 34 & 1.7 \\
\hline Violaxanthin (Viol) & $\mathrm{C}_{40} \mathrm{H}_{56} \mathrm{O}_{4}$ & {$[\mathrm{M}+\mathrm{H}]^{+}$} & 3.29 & 601.4 & 221.0 & 18 & 601.4 & 147.0 & 28 & 0.9 \\
\hline $\begin{array}{l}\text { 19-hex-fucoxanthin } \\
\text { (Hex-fuco) }\end{array}$ & $\mathrm{C}_{46} \mathrm{H}_{68} \mathrm{O}_{8}$ & {$[\mathrm{M}+\mathrm{H}]^{+}$} & 3.55 & 773.5 & 108.9 & 30 & 773.5 & 755.5 & 10 & 1.1 \\
\hline Diadinoxanthin (Diad) & $\mathrm{C}_{40} \mathrm{H}_{54} \mathrm{O}_{3}$ & {$[\mathrm{M}+\mathrm{H}]^{+}$} & 3.91 & 583.5 & 157.1 & 34 & 583.5 & 144.9 & 35 & 0.9 \\
\hline Alloxanthin (Allo) & $\mathrm{C}_{40} \mathrm{H}_{52} \mathrm{O}_{2}$ & {$[\mathrm{M}+\mathrm{H}]^{+}$} & 4.78 & 565.5 & 157.1 & 23 & 565.5 & 119.0 & 32 & 0.9 \\
\hline Zeaxanthin (Zea) & $\mathrm{C}_{40} \mathrm{H}_{56} \mathrm{O}_{2}$ & {$[\mathrm{M}+\mathrm{H}]^{+}$} & 5.86 & 569.4 & 144.9 & 29 & 569.4 & 119.0 & 32 & 0.9 \\
\hline Lutein (Lut) & $\mathrm{C}_{40} \mathrm{H}_{56} \mathrm{O}_{2}$ & {$[\mathrm{M}+\mathrm{H}]^{+}$} & 6.07 & 569.4 & 339.1 & 15 & 569.4 & 144.9 & 29 & 1.7 \\
\hline $\begin{array}{l}8^{\prime} \text {-apo- } \beta, \Psi \text {-Apocarote- } \\
\text { nal (Apo) }\end{array}$ & $\mathrm{C}_{30} \mathrm{H}_{40} \mathrm{O}$ & {$[\mathrm{M}+\mathrm{H}]^{+}$} & 9.20 & 417.3 & 105.2 & 36 & 417.3 & 119.0 & 27 & 1.0 \\
\hline Chlorophyll $b(\mathrm{Chl} b)$ & $\mathrm{C}_{55} \mathrm{H}_{70} \mathrm{O}_{6} \mathrm{Mg}$ & {$[\mathrm{M}+\mathrm{H}]^{+}$} & 12.18 & 907.5 & 569.1 & 38 & 907.5 & 629.0 & 26 & 1.3 \\
\hline $\begin{array}{l}\text { Divinyl chlorophyll } a \\
\qquad(\mathrm{DV} \text { Chl } a \text { ) }\end{array}$ & $\mathrm{C}_{55} \mathrm{H}_{70} \mathrm{~N}_{4} \mathrm{O}_{5} \mathrm{Mg}$ & {$[\mathrm{M}+\mathrm{H}]^{+}$} & 13.67 & 891.5 & 553.0 & 38 & 891.5 & 613.0 & 26 & 1.1 \\
\hline Chlorophyll $a(\mathrm{Chl} a)$ & $\mathrm{C}_{55} \mathrm{H}_{72} \mathrm{~N}_{4} \mathrm{O}_{5} \mathrm{Mg}$ & {$[\mathrm{M}+\mathrm{H}]^{+}$} & 13.97 & 893.5 & 555.0 & 38 & 893.5 & 615.0 & 26 & 0.9 \\
\hline
\end{tabular}

*Ion ratio reported was normalized with respect to the internal standard, lon ratio $=\frac{Q / q}{\mathrm{SS} / \mathrm{ISq}}$ where $Q$ is quantification ion transition, $q$ is confirmation ion transition, ISQ is IS quantification ion transition and ISq is IS confirmation ion transition.

higher responses than atmospheric pressure chemical ionization, especially for polar pigments. Selected reaction monitoring in the positive ion mode was used for the determination of pigments. The optimized ESI conditions were achieved at a vaporizer temperature of $300^{\circ} \mathrm{C}$, spray voltage of $3000 \mathrm{~V}$, sheath gas pressure of 30 (abr), aux gas pressure of 10 (abr) and capillary temperature of $300^{\circ} \mathrm{C}$. LCQUAN 2.6 (Thermo Fisher Scientific, U.S.A.) was used to control the instrument and analyze the acquired data.

The transitions were optimized during product ion scanning by injecting pure standard into the ion source with syringe pump at first, and four abundant product ions were chosen by triple quadrupole instrument. Then, the product ions were deduced from pigment structures to confirm if they can be formed. Subsequently, the transitions with strongest response, the most stable ion ratio and least interference under the method gradient were chosen. The details of the MS/MS parameters are shown in Table 1.

\section{Sample preparation}

Seawater samples were collected from the southern Yellow Sea, China in November 2013. Ten sample sites were selected randomly, and water samples were taken at each site with three in parallel. A seawater volume of $1000 \mathrm{~mL}$ was filtered using a $47 \mathrm{~mm}$ glass fiber filter (GFF) for each sample, and the filter was blotted with a Kimtech cleaning wiper until no moisture remained in order to reduce the matrix effects caused by residual seawater as far as possible, and stored immediately in liquid nitrogen until further analysis.

The pigments were extracted using 100\% methanol. The filters were cut into $2 \mathrm{~mm} \times 5 \mathrm{~mm}$ fragments with scissors and placed in $10 \mathrm{~mL}$ brown glass centrifuge tubes. Extraction was performed by adding $3 \mathrm{~mL}$ of $100 \%$ methanol and $300 \mu \mathrm{L}$ of IS (220 ng mL $\mathrm{mL}^{-1}$ ) on the thawed filter. The tubes were immediately shaken for $30 \mathrm{~s}$ to ensure that the fragments have a homogeneous distribution in methanol. The tubes were then put into an ultrasonic bath filled with ice water for a $10 \mathrm{~min}$ extraction. The extracted solutions were clarified using $0.2 \mu \mathrm{m}$ pore size PTFE syringe filters. Water was immediately added to the injection solvent with a ratio of $1: 5(\mathrm{v} / \mathrm{v})$ to avoid initial peak distortion (Zapata and Garrido 1991; Castells et al. 1997; Castells and Castells 1998) before injection. The preparation was performed under weak light and all the samples were analyzed immediately after preparation.

\section{Standard preparation}

The concentrations of 14 pigment standards purchased from DHI are low, with a range of 788-1755 $\mathrm{ng} \mathrm{mL}^{-1}$. It is difficult to acquire a mixed standard with high concentration and all target pigments, thus 14 types of pigments were 


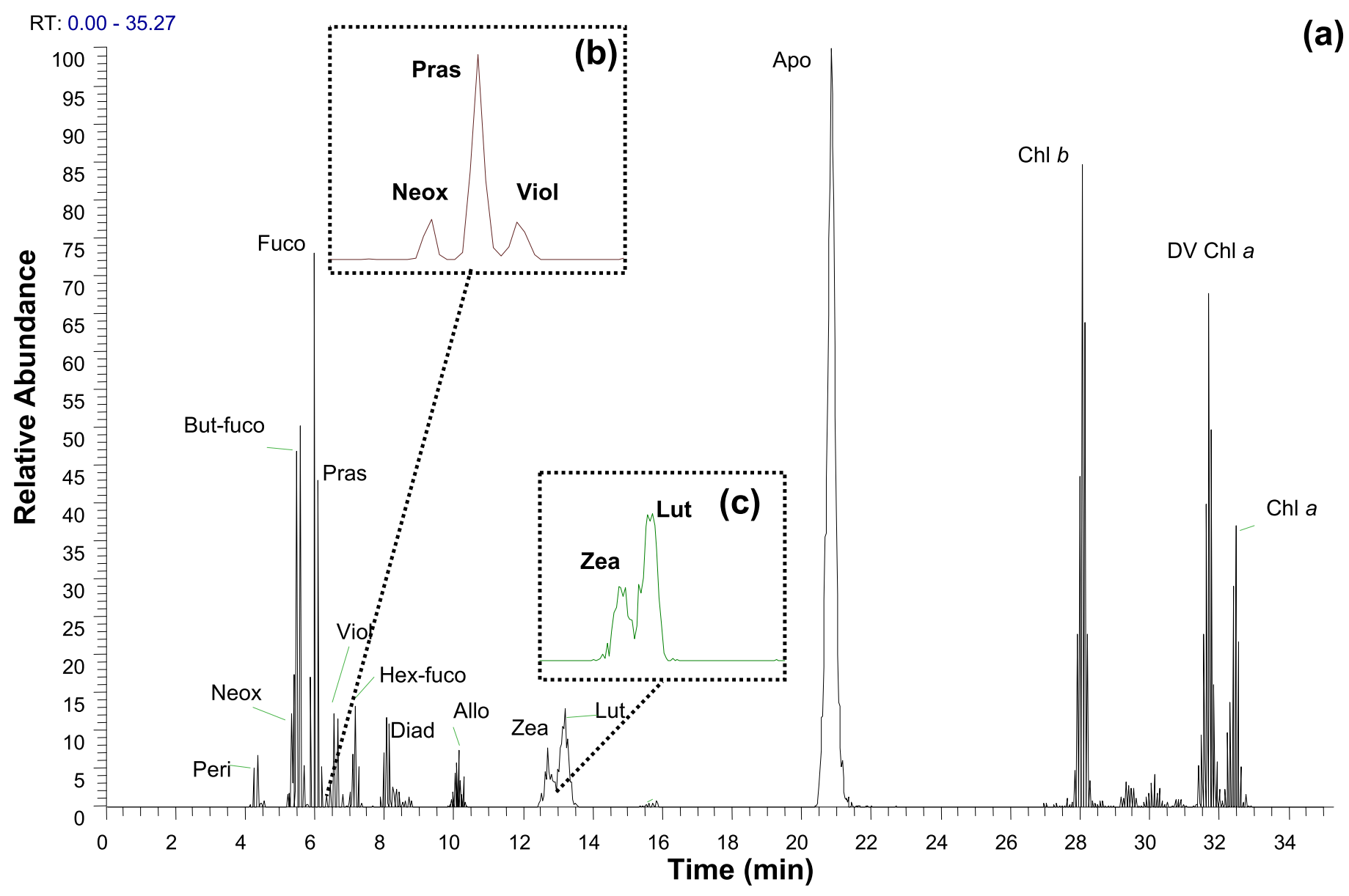

Fig. 1. UHPLC-MS/MS chromatograms of pigments analyzed on Eclipse XDB C8 column at $10 \mathrm{ng} \mathrm{mL}^{-1}$. (a) Total ion chromatogram (TIC) of 14 types of pigments; (b) Selected reaction monitoring (SRM) chromatogram of Neox, Pras and Viol; (c) SRM chromatogram of Zea and Lut.

divided into three groups according to the concentrations of pigments in seawater to prepare working solutions. Group I contained Fuco and Chl $a$, in which the concentrations were the highest; group II contained Peri, Hex-fuco, But-fuco, Diad and $\mathrm{Chl} b$; group III contained the remaining pigments. Standard stock solutions of Chl $a$ and Fuco were prepared to concentrations of $700 \mathrm{ng} \mathrm{mL} \mathrm{m}^{-1}$, mixed standard solutions of groups II and III were prepared to $200 \mathrm{ng} \mathrm{mL}^{-1}$ and $110 \mathrm{ng}$ $\mathrm{mL}^{-1}$, respectively. A matrix blank solution was acquired using filtered seawater (filtering through a GFF filter) following the method used for pigments extraction (see section of Sample preparation). Working solutions were prepared by diluting stock solutions in the matrix blank solution at eight concentration levels. Apo was prepared in methanol to a concentration of $220 \mathrm{ng} \mathrm{mL} \mathrm{m}^{-1}$. The working solutions of different concentrations of the Apo IS were prepared by adding $100 \mu \mathrm{L}$ of $220 \mathrm{ng} \mathrm{mL}^{-1}$ Apo into $1000 \mu \mathrm{L}$ solutions to achieve a $10 \mathrm{ng} \mathrm{mL}{ }^{-1}$ Apo concentration in the injection solution. All of the prepared solutions were stored in Thermo ultra low temperature freezers at $-86^{\circ} \mathrm{C}$ in the dark before analysis within one month. The response ratio (pigments to Apo) vs. pigment concentration was plotted as the calibration curve.

\section{Method validation}

The analytical method was validated using the following criteria: LOQ, linearity, matrix effect, repeatability [intra-day precision expressed as the intra-day relative standard deviation (RSDr)], reproducibility [inter-day precision expressed as the inter-day relative standard deviation (RSDR)] and recovery. The linearity of the method was determined by duplicate analysis of the standard working solutions three times, and the coefficient of determination $\left(R^{2}\right)$ of 14 pigments was calculated. The LOQ was determined in triplicate by diluting the spiked matrix with matrix blank solution to concentrations of $10 \mathrm{ng} \mathrm{mL}{ }^{-1}$, which was defined as the concentration with a signal-to-noise ratio of at least 10 . The effective LOQ of the seawater samples was calculated as follows: 


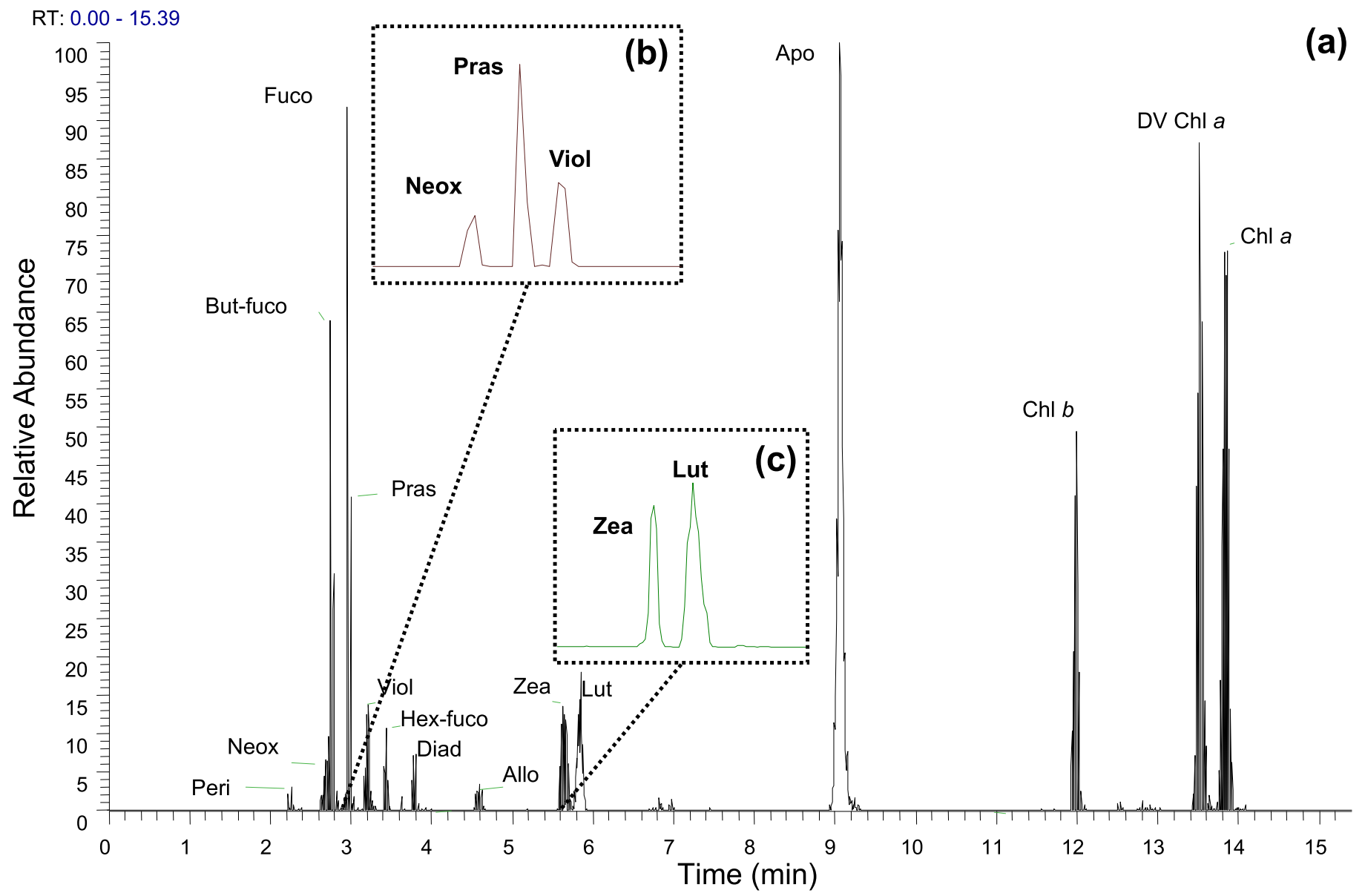

Fig. 2. UHPLC-MS/MS chromatograms of pigments analyzed on Eclipse plus C8 column at $10 \mathrm{ng} \mathrm{mL}^{-1}$. (a) TIC of 14 types of pigments; (b) SRM chromatogram of Neox, Pras and Viol; (c) SRM chromatogram of Zea and Lut.

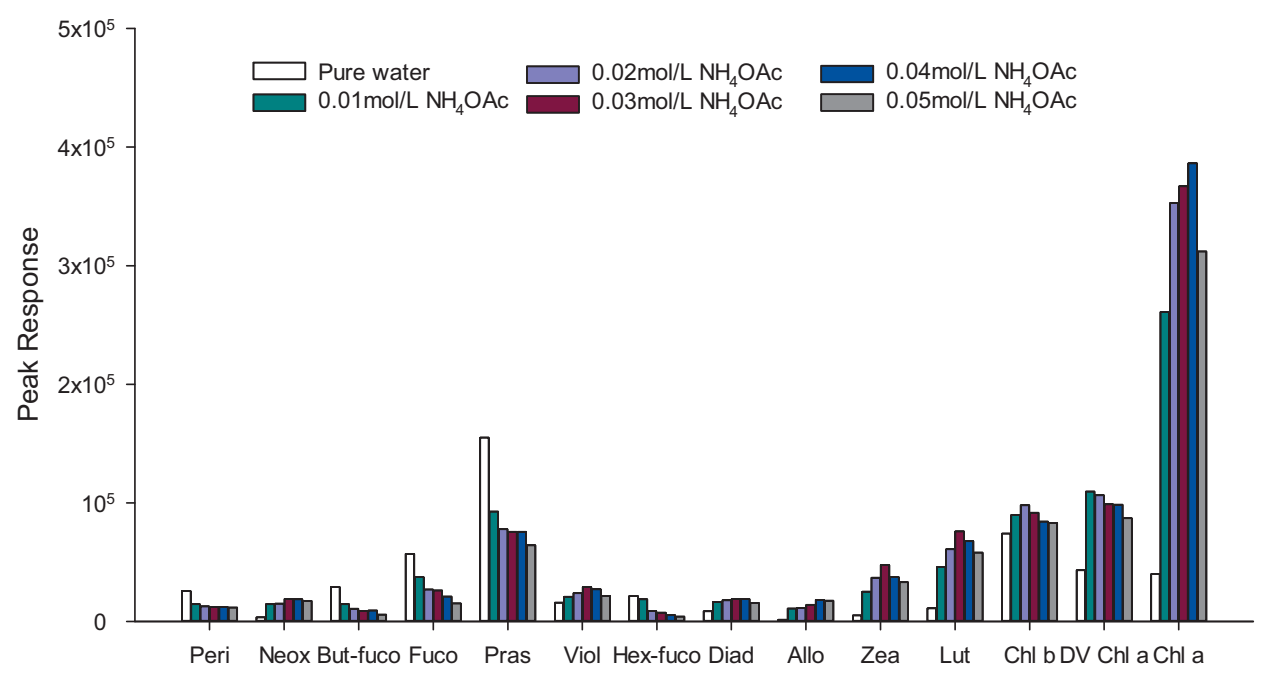

Fig. 3. Peak response of 14 types of pigments under different concentrations of ammonium acetate solution $\left(\mathrm{NH}_{4} \mathrm{OAc}\right)$. 


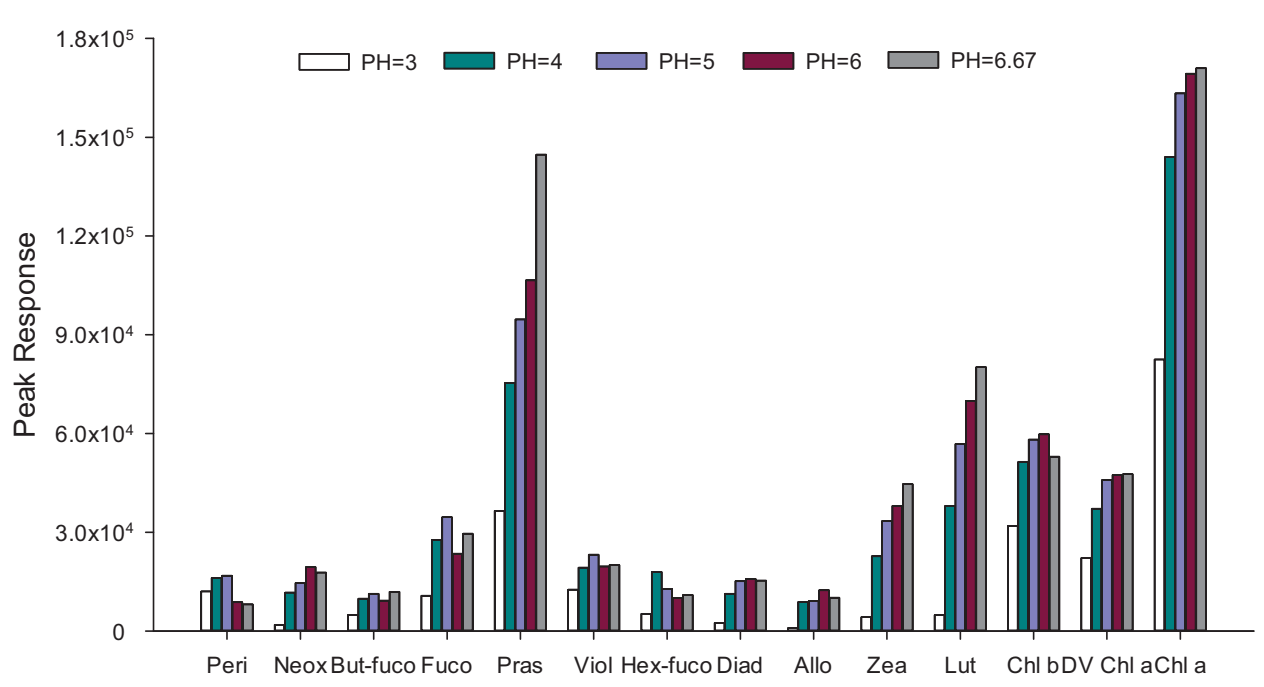

Fig. 4. Peak response of 14 types of pigments under different $\mathrm{pH}$.
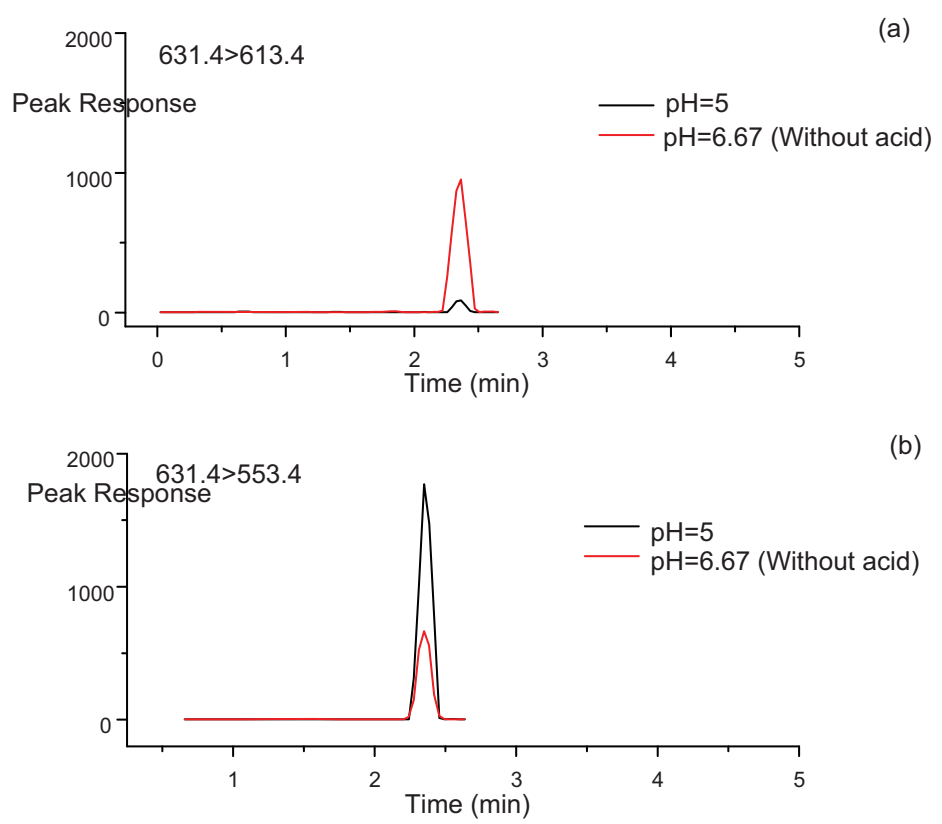

Fig. 5. Peak response comparison of peridinin product ions under different pH. (a) Qualitative ion; (b) Quantitative ion.

$$
\text { effective LOQ }=\frac{L O Q \times V_{\text {extracted }}}{f \times V_{\text {sample }} \times f^{\prime}}
$$

Where LOQ was the limit of quantification in the matrix, $V_{\text {extracted }}$ was the volume of the extracting solution $(3 \mathrm{~mL}), f$ was the dilution rate $(5 / 6), V_{\text {sample }}$ was the volume of the filtrate water samples $(1000 \mathrm{~mL})$, and $f^{\prime}$ was the average recovery of two spiked concentrations.

The matrix effect was normalized by IS and evaluated in triplicate by comparing the response ratio (pigments to Apo) in the extraction solvent with the spiked matrix blank at

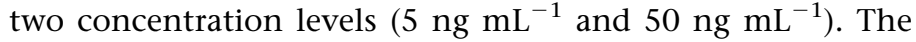
Matrix effects were calculated using equation as follows:

$$
\text { Matrix effects }(\%)=\left(\frac{A 2}{A 1}-1\right) \times 100
$$

Where $A 1$ was the average response ratio of the mix pigment standard in extraction solvent (Methanol) and $A 2$ was the average response ratio of the mix pigment standard in matrix blank at the same concentration. The negative result indicates suppression (decrease the detector response), and the positive result indicates enhancement (increase the detector response).

Ten GFF glass fiber filters with phytoplankton were extracted using $30 \mathrm{~mL}$ of pure methanol in $100 \mathrm{~mL}$ brown glass centrifuge tubes. The mixed extracted solutions were divided into several copies and processed through the procedure of extraction and analysis to determine repeatability, reproducibility and recovery. Both RSDr and RSDR were evaluated by spiking the mixed standard solutions with the phytoplankton extracting solution to two different concentration

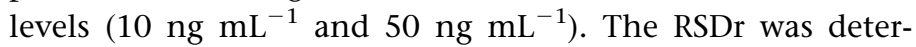
mined by comparing the standard deviations of the spiked solutions on the same day. The RSDR was evaluated by analyzing five replicates on three different days. The recovery was evaluated in triplicate at two different levels $\left(10 \mathrm{ng} \mathrm{mL}^{-1}\right.$ and 50 ng $\left.\mathrm{mL}^{-1}\right)$.

\section{Assessment}

\section{Optimization of UPLC-MS/MS conditions}

Pigment separation is a highly important step for qualitative and quantitative analysis. The application of MS/MS can improve the selectivity of pigments with no need to completely separate all analytes. However, MS/MS detection is unable to quantify pigment isomers accurately if they cannot 
Table 2. Linear ranges, coefficients of determination $\left(R^{2}\right)$ and limit of quantification (LOQ) of 14 types of pigments.

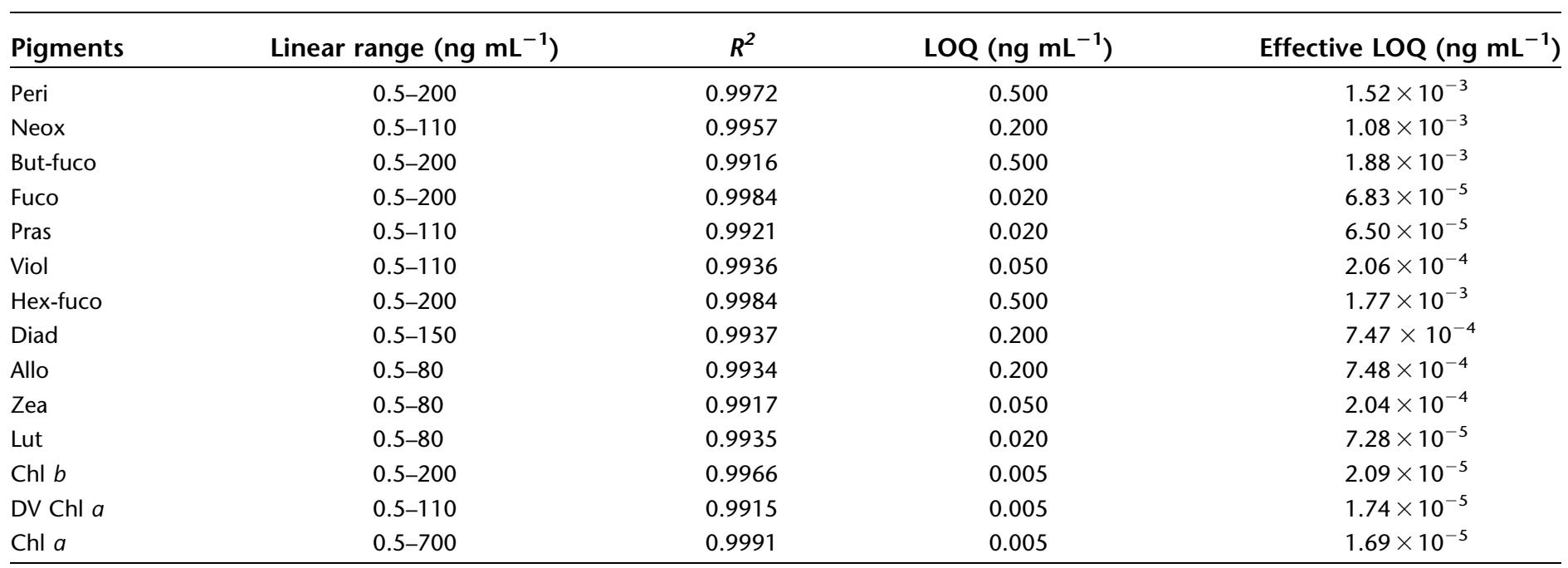

achieve baseline separation in HPLC. Among the 14 pigments, three structural isomer pigments (Neox, Pras, Viol) have the same mass-to-charge ratio of $601.4 \mathrm{~m} / \mathrm{z}$, and another two structural isomer pigments (Zea, Lut) both have a ratio of $569.4 \mathrm{~m} / \mathrm{z}$ (Table 1). Hence, it is important to separate them with HPLC. Two silica-based columns were used for the optimization of pigment separation. The Agilent Eclipse XDB C8 column $(4.6 \mathrm{~mm} \times 100 \mathrm{~mm}, 5 \mu \mathrm{m}$ particle size $)$ achieved good resolution of three pigments (Neox, Pras and Viol) (Fig. 1b), while the other two structural isomer pigments (Zea, Lut) lacked resolution (Fig. 1c). The Agilent Eclipse Plus C8 column with a smaller particle size $(2.1 \mathrm{~mm} \times 100 \mathrm{~mm}, 1.8 \mu \mathrm{m}$ particle size) improved the resolution of Zea/Lut (Fig. 2c). Under the optimized gradient program, all of the structural isomer pigments reached baseline separation (Fig. 2).

Pure water and five concentrations of ammonium acetate solution $\left(0.01,0.02,0.03,0.04\right.$, and $\left.0.05 \mathrm{~mol} \mathrm{~L}^{-1}\right)$ were examined in this study. The variability of pigment responses at different concentrations of ammonium acetate solution ( $\mathrm{NH}_{4} \mathrm{OAc}$ ) was evaluated by analysis of variance (ANOVA). The results showed that $\mathrm{NH}_{4} \mathrm{OAc}$ concentrations significantly affect the response values of pigments $(p<0.05$ for all pigments except Chl $b$ which $p=0.490$ ) (Appendix I). The effects on 14 types of pigments can be divided into three categories (Fig. 3), which correspond to increased ammonium acetate concentration. One category is gradually decreasing response values (e.g., Peri, Fuco, and Pras), the second is gradually increasing response values (e.g., Allo), and the third is increasing at first and then gradually decreasing after reaching the maximum response values (e.g., Zea, Lut, and $\mathrm{Chl} b$ ). After the comparison, the concentrations of $0.02 \mathrm{~mol}$ $\mathrm{L}^{-1}$ and $0.03 \mathrm{~mol} \mathrm{~L}^{-1}$ were found to work better than the other concentrations. Some real seawater samples were analyzed for selecting the concentration of the ammonium acetate solution. The results showed that the concentrations of
Neox, Zea, Lut and Viol were lower than the other pigments (see section on Determination of the pigments in seawater samples).

In this study, formic acid was chosen to adjust the $\mathrm{pH}$ of the ammonium acetate solution, and five different $\mathrm{pH}$ levels $\left[\mathrm{pH}=3,4,5,6,6.67\left(0.03 \mathrm{~mol} \mathrm{~L}^{-1}\right.\right.$ ammonium acetate without additional acid)] were chosen for testing the appropriate acidity. Similarly, significant differences of pigment responses were observed at different $\mathrm{pH}$ levels by ANOVA ( $p<0.05$ for all pigments) (Appendix I). The results showed that the mass spectrum response of Peri, Fuco, Viol, Hexfuco and Chl $b$ increased after adding formic acid, while the other target compounds hardly improved (Fig. 4). In addition, adding formic acid reduced the response of the confirmation product ion of Peri (Fig. 5). The abundance of the qualitative fragment ion $(613.4 \mathrm{~m} / \mathrm{z})$ significantly decreased (Fig. 5a), although the abundance of the quantitative ion $(553.4 \mathrm{~m} / \mathrm{z}$ ) improved under pH 5 (Fig. 5b). Therefore, $0.03 \mathrm{~mol} \mathrm{~L}^{-1}$ ammonium acetate without additional acid was selected for analysis.

\section{Method validation}

The linearity and the LOQ were determined using matrix blank which obtained by the filtered seawater, and the effective LOQ was calculated with formula I. At least six different concentrations of 14 pigments were used to obtain the working curves (Appendix II). The linear regression results and the LOQ were summarized in Table 2. The linear ranges of the 14 pigments were $0.5 \mathrm{ng} \mathrm{mL}^{-1}$ to $80 \mathrm{ng} \mathrm{mL}^{-1}$ (Allo, Zea and Lut), $0.5 \mathrm{ng} \mathrm{mL}^{-1}$ to $110 \mathrm{ng} \mathrm{mL}^{-1}$ (Neox, Pras, DV Chl $a$ and Viol), $0.5 \mathrm{ng} \mathrm{mL}^{-1}$ to $150 \mathrm{ng} \mathrm{mL}^{-1}$ (Diad), $0.5 \mathrm{ng}$ $\mathrm{mL}^{-1}$ to $200 \mathrm{ng} \mathrm{mL}^{-1}$ (Fuco, Hex-fuco, But-fuco, Chl $b$, and Peri), and $0.5 \mathrm{ng} \mathrm{mL}^{-1}$ to $700 \mathrm{ng} \mathrm{mL}^{-1}$ (Chl $a$ ). The $R^{2}$ of all pigments was greater than 0.9915. The LOQ of 14 types of pigments ranged from $0.005 \mathrm{ng} \mathrm{mL}^{-1}$ to $0.500 \mathrm{ng} \mathrm{mL} \mathrm{m}^{-1}$, 


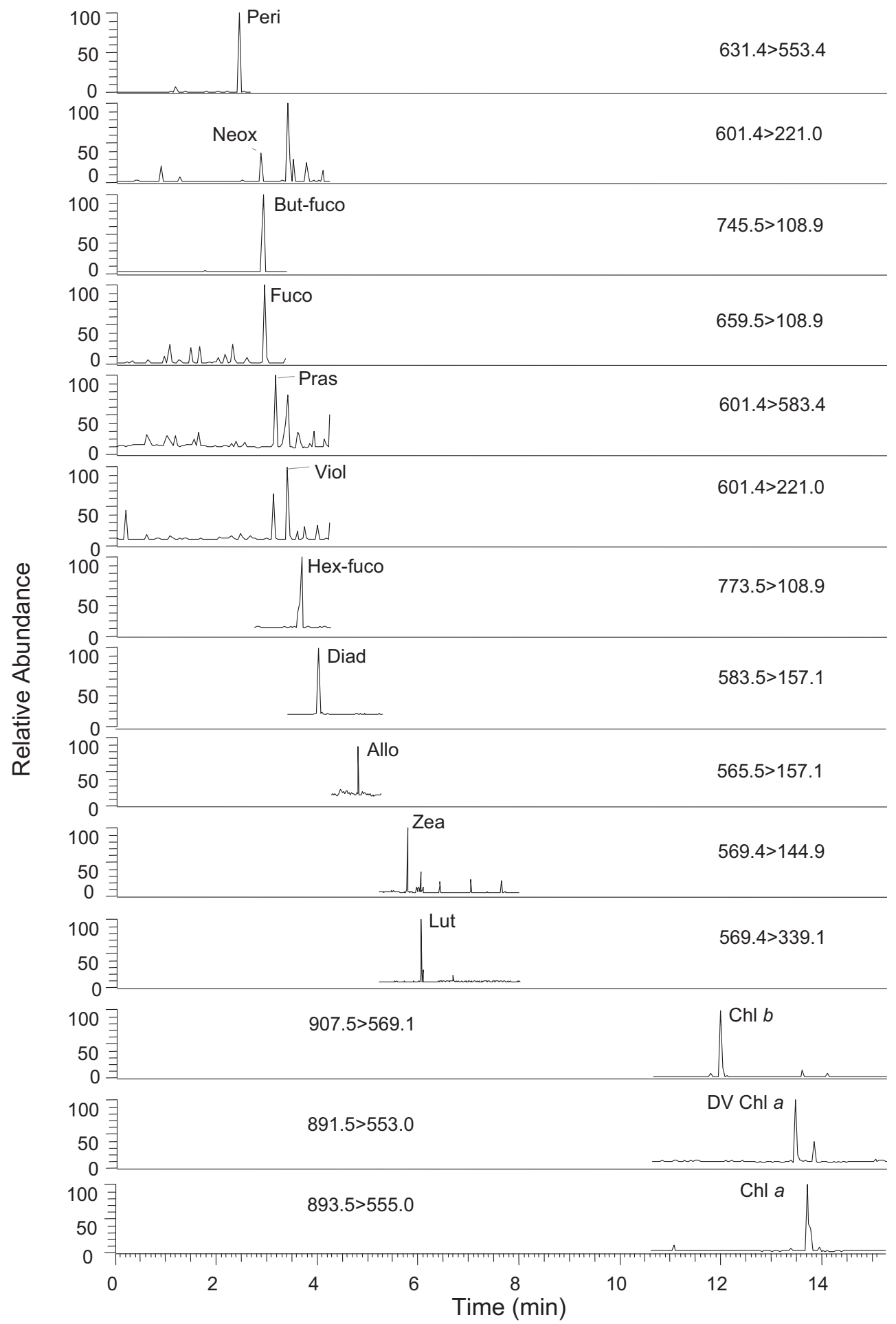

Fig. 6. The SRM chromatograms of 14 pigments at matrix detection limit.

which enabled accurate quantification of seawater samples from $1.69 \times 10^{-5} \mathrm{ng} \mathrm{mL}{ }^{-1}$ to $1.88 \times 10^{-3} \mathrm{ng} \mathrm{mL}^{-1}$. The developed method showed high selectivity, with no obvious interference at the detection limit level in the matrix (Fig. 6), and high sensitivity, which was sufficient for analysis of ultra-trace amounts of phytoplankton pigments in seawater. 
Table 3. Intra-day repeatability (RSDr), inter-day reproducibility (RSDR), matrix effect and recovery obtained for 14 types of pigments at two spiked levels.

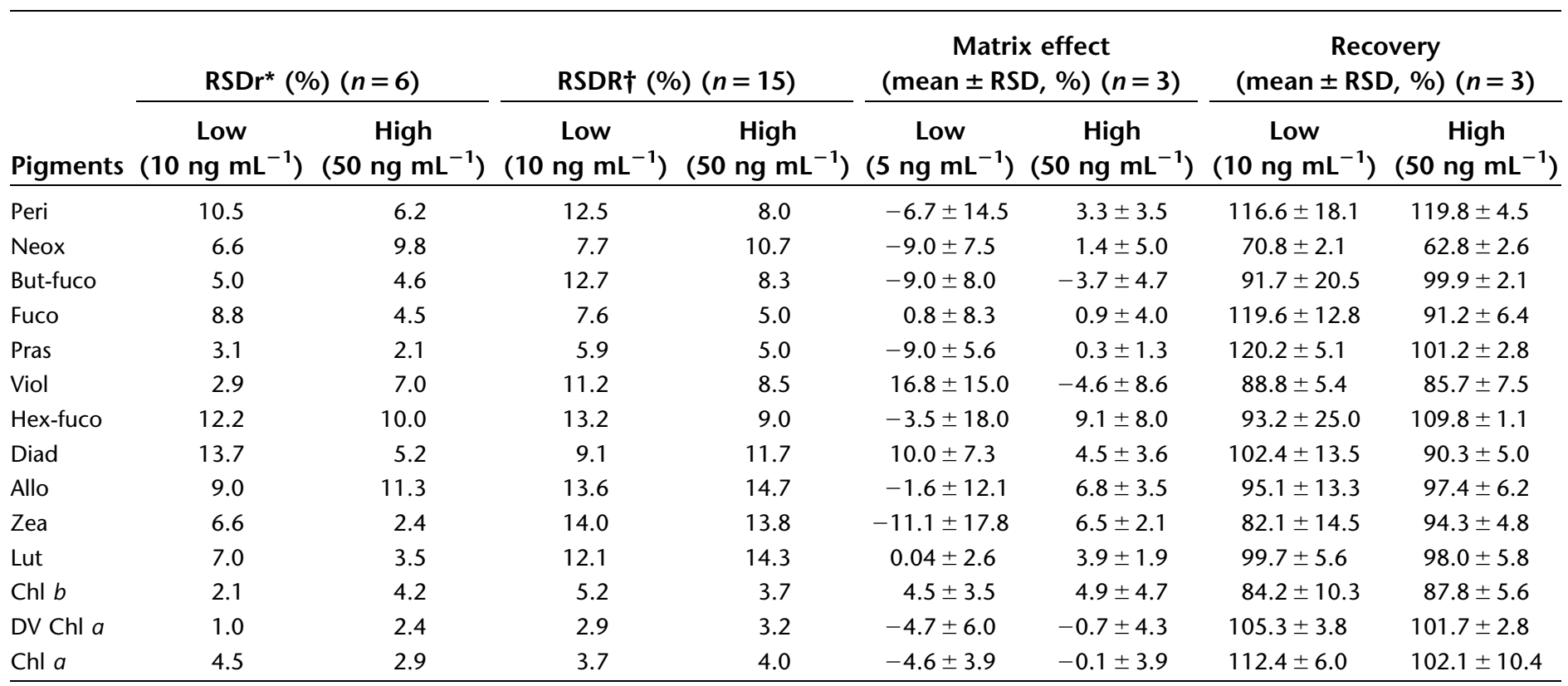

*Intra-day precision for peak area.

†Inter-day precision for peak area.

Table 4. Pigment contents in seawater samples of the Yellow Sea.

\begin{tabular}{|c|c|c|c|c|c|c|c|c|c|c|c|c|c|c|}
\hline \multirow[b]{2}{*}{ Concentration } & \multicolumn{14}{|c|}{ Average concentrations of samples $\left(\mathrm{ng} \mathrm{mL}^{-1}\right)$} \\
\hline & Peri & Neox* & But-fuco & Fuco & Pras & Viol & Hex-fuco & Diad & Allo* & Zea & Lut* & Chl $b$ & $\begin{array}{c}\text { DV Chl } \\
a^{*}\end{array}$ & Chl $a$ \\
\hline Maximum & 0.0469 & 0.0028 & 0.0538 & 0.2412 & 0.0245 & 0.0042 & 0.2926 & 0.0050 & 0.0039 & 0.055 & $0.0009^{\star}$ & 0.1675 & 0.0027 & 0.8806 \\
\hline Minimum & 0 & 0 & 0 & 0.0840 & 0.0003 & 0 & 0.0096 & 0.0005 & 0 & 0.0002 & 0 & 0.0246 & 0.0004 & 0.2187 \\
\hline Average & 0.0161 & $0.0006^{*}$ & 0.0144 & 0.1745 & 0.0085 & 0.0011 & 0.0781 & 0.0024 & $0.0013^{*}$ & 0.0121 & $0.0002^{*}$ & 0.0843 & $0.0013^{*}$ & 0.4303 \\
\hline
\end{tabular}

*The pigments cannot be detected in previous methods (injection volume calculated by $900 \mu \mathrm{L}$, Van Heukelem and Thomas 2001 ).

Thus, it is suggested that the method is feasible for natural samples, and suitable for the research of phytoplankton chemotaxonomy in open sea particularly for oligotrophic waters.

The precision of the method was determined by the RSDr and RSDR, and the accuracy was validated by spiked recovery. The RSDr and RSDR and recovery were evaluated with natural sample at two spiked concentration levels. The matrix effect by IS-normalized was calculated using formula II at two concentration levels. The RSDr and RSDR ranged between $1.0-13.7 \%$ and $2.9-14.7 \%$, respectively (Table 3). The matrix effects and the recoveries were in the range of -11.1 to 16.8 and $62.8 \%$ to $120.2 \%$, respectively (Table 3 ). The RSDr, RSDR, matrix effect and recovery fell within in acceptable ranges for 14 pigments (FDA 2001), except that the recovery of Neox was slightly lower. Therefore, the method was suitable for phytoplankton pigment analysis in seawater.

\section{Determination of the pigments in seawater samples}

Seawater samples are more complex than mixed standard solutions, so it is very important to verify the practicality of the method for seawater samples. In this study, seawater samples from the Yellow Sea were analyzed to test the stability of the method. Phytoplankton are diverse in seawater, and pigment concentrations are variable. In this study, the concentrations of Chl $a$ and Fuco were much higher than the other pigments, ranging from $0.2187 \mathrm{ng} \mathrm{mL}^{-1}$ to 0.8806 $\mathrm{ng} \mathrm{mL} \mathrm{m}^{-1}$ and $0.0840 \mathrm{ng} \mathrm{mL}^{-1}$ to $0.2412 \mathrm{ng} \mathrm{mL}^{-1}$, respectively; and the other pigments were at relatively lower 

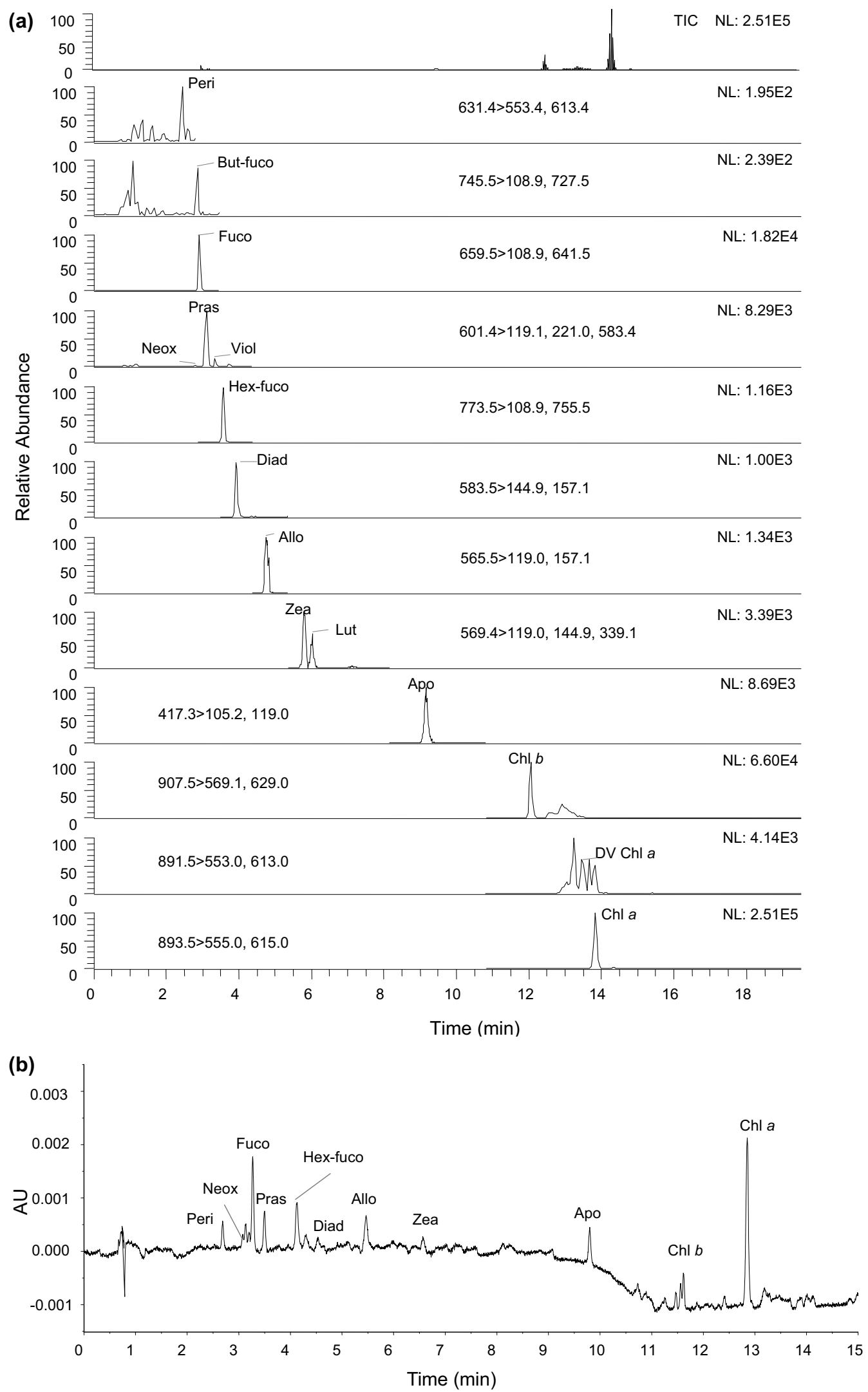

Fig. 7. Phytoplankton pigment Chromatograms of seawater samples from the South Yellow Sea. (a) UV/vis Chromatogram * (absorbance 440 nm); (b) TIC and SRM chromatograms. * The UV/vis chromatogram was provided by Waters Acquity UPLC system. 
Table 5. Comparison of four methods used for pigment analysis.

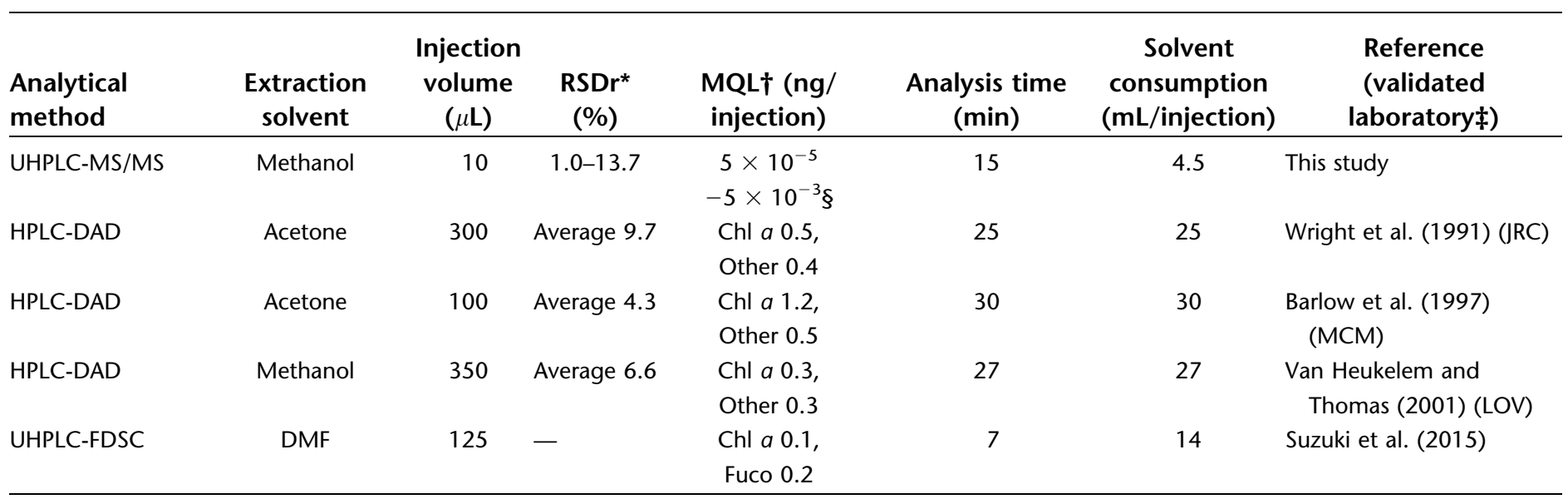

*Intra-day precision for peak area.

$\dagger$ Method quantitative limit.

$¥$ Three HPLC-DAD methods were validated by international laboratories and the validation parameters were derived from the literature of Claustre et al. (2004). JRC: The European Joint Research Centre, MCM: The South African Marine and Coastal Management, LOV: The French Laboratoire d'Océanographie de Villefranche.

$\S$ The MQL in this study was calculated by the following equation to get a better comparison with other methods: MQL $=L O Q \times$ injection volume.

concentrations present average concentrations from 0.0002 $\mathrm{ng} \mathrm{mL} \mathrm{m}^{-1}$ to $0.0781 \mathrm{ng} \mathrm{mL}^{-1}$ (Table 4 ). In contrast, the detection limits in previous methods were too high to detect some pigments with low concentrations (Neox, Allo, Lut, DV Chl a), even using the maximum injection volume (Table 4). Moreover, our method showed less interference and higher sensitivity for natural samples than ultravioletvisible (UV-Vis) chromatography (Fig. 7). Fourteen pigments were all detected in a seawater sample from the southern Yellow Sea (Fig. 7a), but But-fuco, Lut and DV Chl $a$ were absence in UV-Vis spectra (Fig. 7b). In addition, we detected ultra-trace DV Chl a (distinct marker pigment of Prochlorophyta) in the southern Yellow Sea, which was not found in a previous study (Liu et al. 2015), demonstrating that our method can detect pigments at trace or ultra-trace levels in complex seawater samples.

\section{Discussion}

Pigment separation is a highly important step for qualitative and quantitative analysis. The main factors affecting the pigment separation were the column, the mobile phase and the gradient program. Various reversed-phase columns (C8C30) have been used for pigment analysis with gradient elution (Jeffrey et al. 1999; Sander et al. 2000; Zapata et al. 2000; Airs et al. 2001; Van Heukelem and Thomas 2001). Van Heukelem and Thomas (2001) compared the separation characteristics of columns for pigment analysis and found that the Eclipse XDB C8 silica-based column provided better analysis and separation efficiency than the other columns.
In this study, the Agilent Eclipse Plus C8 column improved the resolution of Zea/Lut under the optimized gradient program (Fig. 2) compared with Eclipse XDB C8 silica-based column. The mobile phase is another important factor for pigment separation. Ammonium acetate is often used to improve the peak shape of natural extracts (Jeffrey et al. 1999; Evans et al. 2000) and to stabilize the pigments during analysis (Zapata et al. 1987) with the concentrations ranged from $0.01 \mathrm{~mol} \mathrm{~L}^{-1}$ to $1 \mathrm{~mol} \mathrm{~L}^{-1}$ (Barlow et al. 1997; Airs et al. 2001; Van Heukelem and Thomas 2001). Many other different reagents (e.g., pyridine, TBAA and diazomethane) were used in the mobile phase to acquire good resolution of pigments (Wright et al. 1991; Zapata et al. 2000; Van Heukelem and Thomas 2001). However, the above reagents cannot be used in mass spectrometry analysis, and the concentration of ammonium acetate solution cannot exceed $0.05 \mathrm{~mol}$ $\mathrm{L}^{-1}$. In addition, appropriate acidity can enhance the response of MS in the positive ion mode (Sulyok et al. 2010; Yogendrarajah et al. 2013). Pigment analyses were often carried out in acidic conditions in previous studies (Zapata et al. 2000; Van Heukelem and Thomas 2001). The present study showed that the concentrations of ammonium acetate and the acidity exhibited different influence on the response values of different pigments (Figs. 3, 4). Therefore, the appropriate concentration of ammonium acetate and acidic condition should be chosen according to the target pigments.

Different laboratories used different extraction solvents (Table 5). At present, there are three main kinds of pigment extraction solvents (acetone, methanol and dimethyl 
formamide). dimethyl formamide showed the best extracting effect, but it has high toxicity and is easy to be absorbed by skin. Compared with acetone, methanol has lower volatility, sharper chromatography peaks and superiority for Chl $b$ extraction (Wright et al. 1997), although it may cause the oxidation of Chls (Diehn and Seely 1968). Thus, pure methanol with sonication extraction was recommended as the second best extraction method (Wright and Jeffrey 2006). A recent study found that acetone as injection solvent could result in significant polar pigments peak asymmetry and splitting (Hooker et al. 2009). Thus, the pigments were extracted using $100 \%$ methanol in this study.

Matrix effect caused adverse impact on analytical results often occurs when using LC-MS or MS/MS to analyze complicated samples, and this could be reduced or eliminated by compensating the alteration in signal through the use of an appropriate IS, preferably a stable isotope labeled IS (Stokvis et al. 2005). The isotopically labeled IS of pigments are currently commercially unavailable, and thus need to be synthesized in the laboratory which is both costly and time consuming. In this study, Apo, which is stable and nonexistent in natural samples, was chosen as the IS and the ISnormalized matrix effects was evaluated (Table 3 ). The result showed that the matrix effects of 14 pigments were lower than $\pm 20 \%$, which was at a tolerable level (FDA 2001), and indicated the feasibility of using Apo as IS for pigments analysis in LC-MS/MS.

The linearity, sensitivity, precision and accuracy are important parameters for evaluating a new pigment analysis method and validating the utilization of IS (Hooker et al. 2009). However, it is difficult to acquire a matrix blank for linearity and LOQ analysis and a uniform field sample filter for precision and accuracy validation due to the ubiquitous and inhomogeneous distribution of phytoplankton in seawater. Therefore, the linearity and LOQ were evaluated using standard solutions in many reported methods although these parameters are generally determined using a sample blank (Wright et al. 1991; Zapata et al. 2000; Airs et al. 2001; Van Heukelem and Thomas 2001). Previous studies often validated the RSD by replicate injections of the sample (Van Heukelem and Thomas 2001), and the spiked recoveries were not commonly determined (Bidigare et al. 2005; Hooker et al. 2009). In the Sea-viewing Wide Field-of-view Sensor HPLC Analysis Round-Robin Experiment activity, researchers tried to acquire standard replicates in a reasonable amount of time through filtering water which was continuously mixed in a single carboy covered with black plastic (Hooker et al. 2009). The present study applied filtered seawater to acquire the matrix blank and used mixed extracted solutions to evaluate RSD and recoveries.

Compared with other four methods used for pigment analyses (Table 5), our method shows three advantages. First, method detection limit was reduced by 10 to 1000 times for 14 pigments (Claustre et al. 2004; Hooker et al. 2009; Suzuki et al. 2015), and high selectivity of selected reaction monitoring scan can identify similar compounds by the different product ions or ion ratios. Improved selectivity and sensitivity can significantly reduce false positive or negative signals in HPLC analysis. Second, the sample injection volume was reduced to $10 \mu \mathrm{L}$. In previous studies, the injection volume can reach to $350 \mu \mathrm{L}$ for increasing detection sensitivity, which could result in the distortion of chromatographic peaks for early eluting pigments (Zapata and Garrido 1991; Latasa et al. 2001; Van Heukelem and Thomas 2001). More recently, a large injection volume method was provided without affecting the early eluting chromatographic peaks (Latasa et al. 2014). However, the resolution of compounds may decrease with increases in the injection volume (Ren et al. 2013). Third, our method greatly decreased the analysis time and the organic solvent consumption. The analysis only takes $15 \mathrm{~min}$ and requires $4.5 \mathrm{~mL}$ of solution for each injection, which can improve the efficiency of detection and reduce environmental pollution.

\section{Comments}

The UHPLC-MS/MS method developed for analyzing complex seawater samples displays high sensitivity and accuracy for targeting pigments at trace/ultra-trace levels. Compared to previous methods, this method greatly reduced the consumption of organic solvent and analysis time. Therefore, further exploration of more pigments in the future is warranted, and may lead to the wider application of this method in chemotaxonomy.

\section{References}

Airs, R. L., J. E. Atkinson, and B. J. Keely. 2001. Development and application of a high resolution liquid chromatographic method for the analysis of complex pigment distributions. J. Chromatogr. A 917: 167-177. doi:10.1016/ s0021-9673(01)00663-X

Airs, R. L., and C. A. Llewellyn. 2006. Improved detection and characterization of fucoxanthin-type carotenoids: Novel pigments in Emiliania huxleyi (Prymnesiophyceae). J. Phycol. 42: 391-399. doi:10.1111/j.1529-8817.2006.001 99.x

Airs, R. L., and J. L. Garrido. 2011. Liquid chromatographymass spectrometry for pigment analysis, p. 314-342. In S. Roy, C. A. Llewellyn, E. S. Egeland, and G. Johnsen [eds.], Phytoplankton pigments: Characterization, chemotaxonomy, and applications in oceanography. Cambridge Univ. Press.

Alvarez, S., M. Zapata, J. L. Garrido, and B. Vaz. 2012. Characterization of [8-ethyl]-chlorophyll c (3) from Emiliania huxleyi. Chem. Commun. 48: 5500-5502. doi:10.1039/ c2cc31329d

Barlow, R. G., D. G. Cummings, and S. W. Gibb. 1997. Improved resolution of mono- and divinyl chlorophylls a 
and $\mathrm{b}$ and zeaxanthin and lutein in phytoplankton extracts using reverse phase C-8 HPLC. Mar. Ecol. Prog. Ser. 161: 303-307. doi:10.3354/meps161303

Bidigare, R. R., L. Van Heukelem, and C. C. Trees. 2005. Analysis of algal pigments by high-performance liquid chromatography, p. 327-345. In R. Andersen [ed.], Algal culturing techniques. Elsevier Academic Press.

Castells, R. C., C. B. Castells, and M. A. Castillo. 1997. Influence of differences between sample and mobile phase viscosities on the shape of chromatographic elution profiles. J. Chromatogr. A 775: 73-79. doi:10.1016/s0021-9673(97) 00343-9

Castells, C. B., and R. C. Castells. 1998. Peak distortion in reversed-phase liquid chromatography as a consequence of viscosity differences between sample solvent and mobile phase. J. Chromatogr. A 805: 55-61. doi:10.1016/ S0021-9673(98)00042-9

Claustre, H., and others. 2004. An intercomparison of HPLC phytoplankton pigment methods using in situ samples: Application to remote sensing and database activities. Mar. Chem. 85: 41-61. doi:10.1016/j.marchem.2003. 09.002

Diehn, B., and G. R. Seely. 1968. Oxidation of chlorophyll alpha in alcohols. Biochimica. Biochim. Biophys. Acta 153: 862-867. doi:10.1016/0005-2728(68)90013-3

Dolan, J. W. 2002. Resolving minor peaks. LC GC N. Am. 20: $594-598$.

Evans, C. S., Startin, J. R., D. M. Goodall, and B. J. Keely. 2000. Improved sensitivity in detection of chlormequat by liquid chromatography-mass spectrometry. J. Chromatogr. A 897: 399-404. doi:10.1016/S0021-9673(00)00814-1

FDA. 2001. Guidance for industry, bioanalytical method validation. US Department of Health and Human Services Food and Drug Administration, Center for Drug Evaluation and Research (CDER). Available from www.fda.gov/downloads/ Drugs/GuidanceComplianceRegulatoryInformation/Guidances/ UCM070107.pdf

Field, C. B., M. J. Behrenfeld, J. T. Randerson, and P. Falkowski. 1998. Primary production of the biosphere: Integrating terrestrial and oceanic components. Science 281: 237-240. doi:10.1126/science.281.5374.237

Frassanito, R., M. Cantonati, M. Tardio, I. Mancini, and G. Guella. 2005. On-line identification of secondary metabolites in freshwater microalgae and cyanobacteria by combined liquid chromatography-photodiode array detectionmass spectrometric techniques. J. Chromatogr. A 1082: 33-42. doi:10.1016/j.chroma.2005.02.066

Frassanito, R., G. Flaim, I. Mancini, and G. Guella. 2006. High production of unexpected carotenoids in Dinophyceae Astaxanthin esters from the freshwater dinoflagellate Tovelliasanguinea. Biochem. System. Ecol. 34: 843-853. doi:10.1016/j.bse.2006.05.013

Garrido, J. L., and M. Zapata. 1997. Reversed-phase highperformance liquid chromatographic separation of monoand divinyl chlorophyll forms using pyridine-containing mobile phases and a polymeric octadecylsilica column. Chromatographia 44: 43-49. doi:10.1007/Bf02466514

Hooker, S. B., L. Van Heukelem, C. S. Thomas, and others. 2009. The third SeaWiFS HPLC analysis round-robin experiment (SeaHARRE-3). NASA Technical Memorandum 2009-215849. NASA Goddard Space Flight Center.

Ives, A. R., and S. R. Carpenter. 2007. Stability and diversity of ecosystems. Science 317: 58-61. doi:10.1126/science.1133258

Jeffrey, S. W., and M. Vesk. 1997. Introduction to marine phytoplankton and their pigment signatures, p. 37-84. In S. W. Jeffrey, R. F. C. Mantoura, and S. W. Wright [eds.], Phytoplankton pigments in oceanography: Guidelines to modern methods. UNESCO.

Jeffrey, S. W., S. W. Wright, and M. Zapata. 1999. Recent advances in HPLC pigment analysis of phytoplankton. Mar. Freshwater Res. 50: 879-896. doi:10.1071/Mf99109

Jeffrey, S. W., and S. W. Wright. 2006. Photosynthetic pigments in marine microalgae, p. 33-90. In D. V. Subba Rao [ed.], Algal cultures, analogues of blooms and applications. Science Publishers.

Latasa, M., K. Van Lenning, J. L. Garrido, R. Scharek, M. Estrada, F. Rodríguez, and M. Zapata. 2001. Losses of chlorophylls and carotenoids in aqueous acetone and methanol extracts prepared for RPHPLC analysis of pigments. Chromatographia 53: 385-391. doi:10.1007/BF02491072

Latasa, M., R. Scharek, F. Le Gall, and L. Guillou. 2004. Pigment suites and taxonomic groups in Prasinophyceae. J. Phycol. 40: 1149-1155. doi:10.1111/j.1529-8817.2004. 03136.x

Latasa, M. 2014. A simple method to increase sensitivity for RP-HPLC phytoplankton pigment analysis. Limnol. Oceanogr.: Methods 12: 46-53. doi:10.4319/lom.2014.12.46

Le Quéré, C., and others. 2005. Ecosystem dynamics based on plankton functional types for global ocean biogeochemistry models. Global Change Biol. 11: 2016-2040. doi:10.1111/j.1365-2468.2005.01004.x

Liu, X., and others. 2015. Seasonal phytoplankton response to physical processes in the southern Yellow Sea. J. Sea Res. 95: 45-55. doi:10.1016/j.seares.2014.10.017

Mackey, M. D., D. J. Mackey, H. W. Higgins, and S. W. Wright. 1996. CHEMTAX - A program for estimating class abundances from chemical markers: Application to HPLC measurements of phytoplankton. Mar. Ecol. Prog. Ser. 144: 265-283. doi:10.3354/Meps144265

Marañón, E., M. J. Behrenfeld, N. González, B. Mouriño, and M. V. Zubkov. 2003. High variability of primary production in oligotrophic waters of the Atlantic Ocean: Uncoupling from phytoplankton biomass and size structure. Mar. Ecol. Prog. Ser. 257: 1-11. doi:10.3354/Meps257001

Ren, D. B., Z. H. Yang, Y. Z. Liang, W. Fan, and Q. Ding. 2013. Effects of injection volume on chromatographic features and resolution in the process of counter-current chromatography. J. Chromatogr. A 1277: 7-14. doi: 10.1016/j.chroma.2012.12.035. 
Roemmich, D., and J. McGowan. 1995. Climatic warming and the decline of zooplankton in the California current. Science 268: 352-353. doi:10.1126/science.268.5209.352-b

Sabine, C. L., and others. 2004. The oceanic sink for anthropogenic $\mathrm{CO}_{2}$. Science 305: 367-371. doi:10.1126/ science. 1097403

Sander, L. C., K. E. Sharpless, and M. Pursch. 2000. C-30 stationary phases for the analysis of food by liquid chromatography. J. Chromatogr. A 880: 189-202. doi:10.1016/ S0021-9673(00)00121-7

Sanz, N., A. García-Blanco, A. Gavalás-Olea, P. Loures, and J. L. Garrido. 2015. Phytoplankton pigment biomarkers: HPLC separation using a pentafluorophenyloctadecyl silica column. Methods Ecol. Evol. 6: 1117-1238. doi: 10.1111/2041-210X.12406

See, J. H., L. Campbell, T. L. Richardson, J. L. Pinckney, and R. Shen. 2005. Combining new technologies for determination of phytoplankton community structure in the northern Gulf of Mexico. J. Phycol. 41: 305-310. doi: 10.1111/j.1529-8817.2005.04132.x

Squier, A. H., D. A. Hodgson, and B. J. Keely. 2004. Structures and profiles of novel sulfur-linked chlorophyll derivatives in an Antarctic lake sediment. Org. Geochem. 35: 1309-1318. doi:10.1016/j.orggeochem.2004.06.016

Squier, A. H., D. A. Hodgson, and B. J. Keely. 2005. Evidence of late Quaternary environmental change in a continental east Antarctic lake from lacustrine sedimentary pigment distributions. Antarct. Sci. 17: 361-376. doi:10.1017/ s0954102005002804

Stokvis, E., H. Rosing, and J. H. Beijnen. 2005. Stable isotopically labeled internal standards in quantitative bioanalysis using liquid chromatography/mass spectrometry: Necessity or not? Rapid Commun. Mass Sp. 19: 401-407. doi: 10.1002/rcm.1790

Sulyok, M., R. Krska, and R. Schuhmacher. 2010. Application of an LC-MS/MS based multi-mycotoxin method for the semi-quantitative determination of mycotoxins occurring in different types of food infected by moulds. Food Chem. 119: 408-416. doi:10.1016/j.foodchem.2009.07.042

Suzuki, K., A. Kamimura, and S. B. Hooker. 2015. Rapid and highly sensitive analysis of chlorophylls and carotenoids from marine phytoplankton using ultra-high performance liquid chromatography (UHPLC) with the first derivative spectrum chromatogram (FDSC) technique. Mar. Chem. 176: 96-109. doi:10.1016/j.marchem.2015.07.010

Van Heukelem, L., and C. S. Thomas. 2001. Computerassisted high-performance liquid chromatography method development with applications to the isolation and analysis of phytoplankton pigments. J. Chromatogr. A 910: $31-$ 49. doi:10.1016s0378-4347(00)00603-4

Van Heukelem, L., and S. B. Hooker. 2011. The importance of a quality assurance plan for method validation and minimizing uncertainties in the HPLC analysis of phyto- plankton pigments, p. 195-242. In S. Roy, C. A. Llewellyn, E. S. Egeland, and G. Johnsen [eds.], Phytoplankton pigments characterization, chemotaxonomy and applications in oceanography. Cambridge Univ. Press.

Wright, S. W., S. W. Jeffrey, R. F. C. Mantoura, C. A. Llewellyn, T. Bjørnland, D. Repeta, and N. Welschmeyer. 1991. Improved HPLC method for the analysis of chlorophylls and carotenoids from marine-phytoplankton. Mar. Ecol. Prog. Ser. 77: 183-196. doi:10.3354/meps077183

Wright, S. W., S. W. Jeffrey, and R. F. C. Mantoura. 1997. Evaluation of methods and solvents for pigment extraction, p. 261-282. In S. W. Jeffrey, R. F. C. Mantoura, and S. W. Wright [eds.], Phytoplankton pigments in oceanography: Guidelines to modern methods. UNESCO.

Wright, S. W., and S. W. Jeffrey. 2006. Pigment markers for phytoplankton production, p. 71-104. In J. K. Volkman [ed.], Marine organic matter: Biomarkers, isotopes and DNA. Springer.

Yogendrarajah, P., C. Van Poucke, B. De Meulenaer, and S. De Saeger. 2013. Development and validation of a QuEChERS based liquid chromatography tandem mass spectrometry method for the determination of multiple mycotoxins in spices. J. Chromatogr. A 1297: 1-11. doi: 10.1016/j.chroma.2013.04.075

Zapata, M., A. M. Ayala, J. M. Franco, and J. L. Garrido. 1987. Separation of chlorophylls and their degradation products in marine-phytoplankton by reversed-phase high-performance liquid-chromatography. Chromatographia 23: 26-30. doi:10.1007/bf02310413

Zapata, M., and J. L. Garrido. 1991. Influence of injection conditions in reversed-phase high-performance liquidchromatography of chlorophylls and carotenoids. Chromatographia 31: 589-594. doi:10.1007/bf02279480

Zapata, M., F. Rodríguez, and J. L. Garrido. 2000. Separation of chlorophylls and carotenoids from marine phytoplankton: A new HPLC method using a reversed phase C-8 column and pyridine-containing mobile phases. Mar. Ecol. Prog. Ser. 195: 29-45. doi:10.3354/meps195029

Zapata, M., S. W. Jeffrey, S. W. Wright, F. Rodríguez, J. L. Garrido, and L. Clementson. 2004. Photosynthetic pigments in 37 species (65 strains) of Haptophyta: Implications for oceanography and chemotaxonomy. Mar. Ecol. Prog. Ser. 270: 83-102. doi:10.3354/meps270083

\section{Acknowledgments}

This work was sponsored by the Natural Science Foundation of China (41376121), the Strategic Priority Research Program of the Chinese Academy of Sciences (XDA11020405) and the Natural Science Foundation of Shandong Province (JQ201414).

Submitted 4 February 2016 Revised 5 May 2016 Accepted 19 May 2016

Associate editor: Krista Longnecker 